\title{
Geç Tanı Almış Morquio Sendromu Olgusu
}

\author{
Late Diagnosis of a Patient with Morquio Syndrome
}

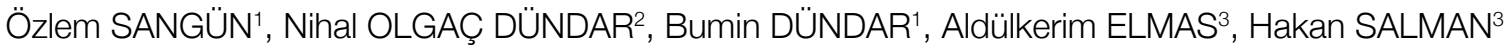

${ }^{1}$ Süleyman Demirel Üniversitesi, Tıp Fakültesi, Çocuk Sağıı̆ı ve Hastalıkları Anabilim Dalı, Pediatrik Endokrinoloji BD, Isparta, Türkiye 2Süleyman Demirel Üniversitesi, Tıp Fakültesi, Çocuk Sağlığı ve Hastalıkları Anabilim Dalı, Pediatrik Nöroloji BD, Isparta, Türkiye

${ }^{3}$ Süleyman Demirel Üniversitesi, Tıp Fakültesi, Çocuk Sağıı̆ı ve Hastalıkları Anabilim Dalı, Isparta,Türkiye

\begin{abstract}
ÖZET
Morquio Tip A Sendromu (MPS IVA) N-asetilgalaktozamin-6-sulfat sulfataz eksikliği ile ortaya çıkan, kornea ve kemikte keratan sülfat ve kondroitin-6-sulfat birikimi ile karakterize, otozomal resesif geçişli bir lizozomal depo hastalı̆ııdır. Başıca klinik bulgular; kısa boy, iskelet displazisi, dental anomaliler ve korneal bulutlanmadir. Bunlara sinirsel tip işitme kaybı, kalp kapağı hastalıkları, eklem laksitesi ve servikal myelopati eșlik edebilir. Merkezi sinir sistemi tutulumunun olmaması sebebiyle enzim replasman tedavisi ve gen tedavilerinin uygulanabileceği bir hastalık olarak kabul edilmektedir. Preklinik çalışmalarda enzim replasman tedavisi ile doku ve kandaki keratan sülfat oranında anlamlı düşüş gösterilmiştir. Ancak lizozomal depo hastalıklarında tedavinin başarıı olabilmesi hastalığın erken dönemlerinde bașlanması ile mümkündür. Bu yazıda, kliniğimize 11 yaş 2 aylık iken, ağır solunum yetersizliği tablosu ile başvuran, yaygın iskelet displazisi bulguları olan ve Morquio Tip A tanısını geç almış olan bir hasta sunulmuştur.
\end{abstract}

Anahtar Sözcükler: Morquio sendromu, Tanı

\begin{abstract}
Morquio Type A Syndrome (Mucopolysaccharidosis IVA) is an autosomal recessive disorder characterized by the lysosomal accumulation of keratan sulfate and chondroitin- 6 sulfate particularly in the bone and cornea due to the deficiency of $\mathrm{N}$-acetylgalactosamine-6-sulfate sulfatase. The major clinical signs are short stature, skeletal dysplasia, dental anomalies, and corneal clouding. Sensorineural hearing loss, valvular heart diseases, joint laxity, and cervical myelopathy can also accompany the disease. As the affected patients do not have central nervous system involvement, the Morquio A syndrome is accepted to be a good candidate for enzyme replacement and gene therapies. Preclinical studies have shown that enzyme replacement treatment enables a significant decrease in tissue and blood keratan sulfate levels, and treatment should be performed as early as possible in lysosomal storage diseases in order to achieve successful curative therapy. In this case report, we present a patient aged 11 years and 2 months who had systemic skeletal dysplasia and was admitted to our hospital with terminal respiratory failure. Unfortunately, the patient was diagnosed as MPS IVA at the late stage of the disease and did not receive any enzyme replacement treatment.
\end{abstract}

Key Words: Morquio syndrome, Diagnosis

\section{GiRiş}

Mukopolisakkaridozlar (MPS), glikozaminoglikanların (GAG) yıkımında görevli lizozomal enzimlerden herhangi birinin eksikliği ile karakterize, kalıtsal lizozomal depo hastalıklarıdır (1-3). Glikozaminoglikanların yıkımında görevli 11 önemli enzimden herhangi birinin eksikliğinde, dermatan sülfat, heparan sülfat, keratan sülfat (KS), kondroitin sülfat ve nadiren hyaluronan yıkımında bozukluklar meydana gelir. Eksik olan enzim ve etkilenen dokularda biriken maddeye göre MPS'lerin Tip 1'den 9'a kadar farklı tipleri bildirilmiş olup toplam MPS insidansı genel olarak 25.000 canlı doğumda birdir (1).

MPS Tip IVA (Morquio A hastallğı) N-asetilgalaktozamin-6-sülfat sülfataz (GALNS) eksikliğine bağlı olarak KS ve kondroitin-6sülfatın esas olarak kornea ve kemikte birikimi ile karakterize bir hastalıktır (3). Klinik bulguları sistemik iskelet displazisi, eklem laksitesi, işitme kaybı, korneal bulutlanma ve kalp kapağı hastalıkları olarak sayılabilir (4). MPS IVA, özellikle merkezi sinir sistemi tutulumunun olmaması sebebiyle enzim replasman tedavisi (ERT)'nin ve gen tedavilerinin uygulanabileceği bir hastallık 
olarak kabul edilmektedir (4). MPS IVA için ERT geliştirilmekte olup, preklinik çalışmalarda bu tedavi ile doku ve kandaki KS oranında anlamlı düşüş gösterilmiştir $(5,6)$. Lizozomal depo hastalıklarının ERT ile tedavisi, somatik belirtilerde gerileme ile birlikte hastalara daha iyi bir yaşam kalitesi sunmaktadır (7). Yakın zamanda tedavisinin mümkün olacağı düşünülen bu hastaların erken tanısı, destek tedavilerinin erken başlatılabilmesinin yanı sıra tedavi şansı verilebilmesi açısından önemlidir.

Bu yazıda, sistemik iskelet displazisi bulguları mevcut olup, kliniğimize ağır solunum yetersizliği tablosu ile başvuran ve tanı almakta gecikmiş MPS IVA'lı bir hasta sunulmuştur.

\section{OLGU SUNUMU}

On bir yaş iki aylık kız hasta, başvurusundan 3 gün önce başlayan halsizlik, iştahsızlık, nefes almada zorluk ve ateş şikayeti ile kliniğimize başvurdu. Özgeçmişinden; normal spontan vajinal yol ile miadında, 3500 gr doğduğu, zor doğum öyküsünün olmadığı, 3 yaşına kadar gelişiminin normal olduğu, daha sonra yürümesi ve gelişmesinin gerilemeye başladığı, farklı merkezlerde yapılan tetkikler sonucu kesin bir tanı konulamadığı ve 1 kez ateşli nöbet geçirdiği öğrenildi. Soy geçmişinden anne ve babasının birinci derece akraba evliliği yaptığı, ailesinde benzer hastalığı olan birey bulunmadığı öğrenildi (Şekil 1). Hastanın konuşmasının ve iletişiminin normal olduğu fakat okuma yazmayı tam öğrenemediği belirtildi.

Hastanın VA: 14 kg (<3p, -6.3 SDS ), Boy: 95 cm (<3p, -10.9 SDS), Baş çevresi: 50 cm (-1.69 SDS) olarak saptandı. Genel durumu orta-kötü, bilinci açık fakat koopere değildi. Atipik, kaba yüz görünümü, genu valgus deformitesi, kısa ve metafizleri geniş ekstremiteleri, ağız içinde çürük ve kayıp dişleri mevcuttu (Şekil 2). Göğüs deformitesi (pektus karinatus), torakolomber kifoz ve açıklığı sağa bakan skolyozu mevcut olan hastanın, solunum sayısı: 50 /dk, dispneik ve dinlemekle kaba ronküsleri vardı. Kardiyovasküler sistem değerlendirmesinde, kalp sesleri ritmik, S1, S2 doğal, ek ses yok ancak mezokardiyak odakta 1/6 sistolik üfürümü mevcuttu. Batın distandü, ancak hepatosplenomegalisi, defans ve reboundu yoktu. Haricen prepubertal doğal kız gö-

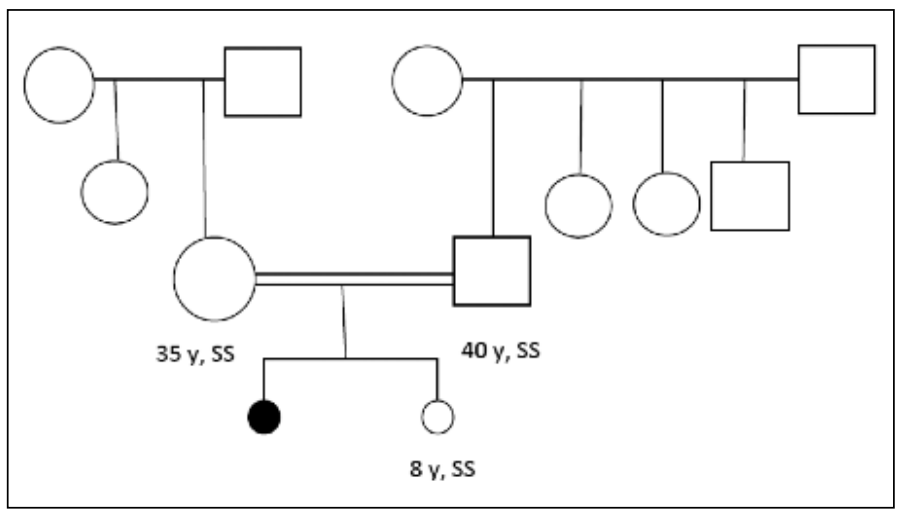

Şekil 1: Hastamızın pedigrisi. rünümünde olan hastanın, nöromüsküler sistem muayenesinde Işık refleksi normal, pupilleri izokorik, meninks irritasyon bulgusu yok, derin tendon refleksleri hiperaktif, babinski iki taraflı plantar yanıt ekstensör, klonus iki taraflı pozitif bulundu. Motor, duyu ve serebellar muayenesi değerlendirilemedi. Göz muayenesinde korneal bulutlanma saptanmadı.

Laboratuvar incelemelerinde rutin kan ve biyokimyasal tetkikleri normal bulunan hastadan MPS ön tanısıyla gönderilen idrar GAG değeri ile metabolik hastalık ön tanısıyla gönderilen aminoasit ve açilkarnitin düzeyleri de normal bulundu. İskelet grafilerinde tüm ekstremitelerin metafizleri geniş, metakarplar ve falankslar kısa ve kalın, skolyoz, platispondili, her iki taraf femur boynunda valgus deformitesi ve kemik yapılarda osteoporotik bulgular saptanan hastanın, çekilen beyin bilgisayarlı tomografisinde patolojik bulgu yoktu (Şekil 3,4). Kifoskolyoz ve

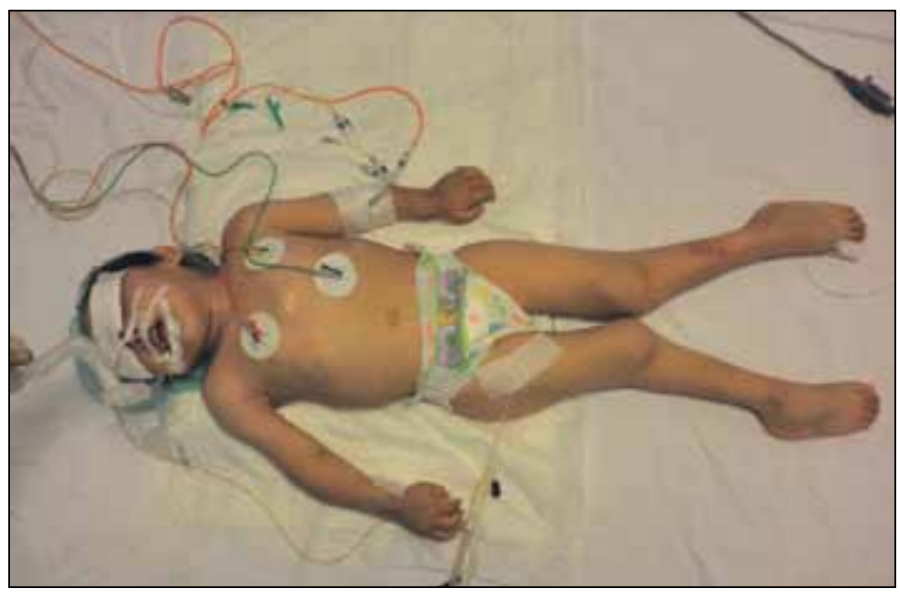

Şekil 2: Mekanik ventilatördeki hastanın genu valgum ve pectus carinatus deformitesi gözlenmektedir.

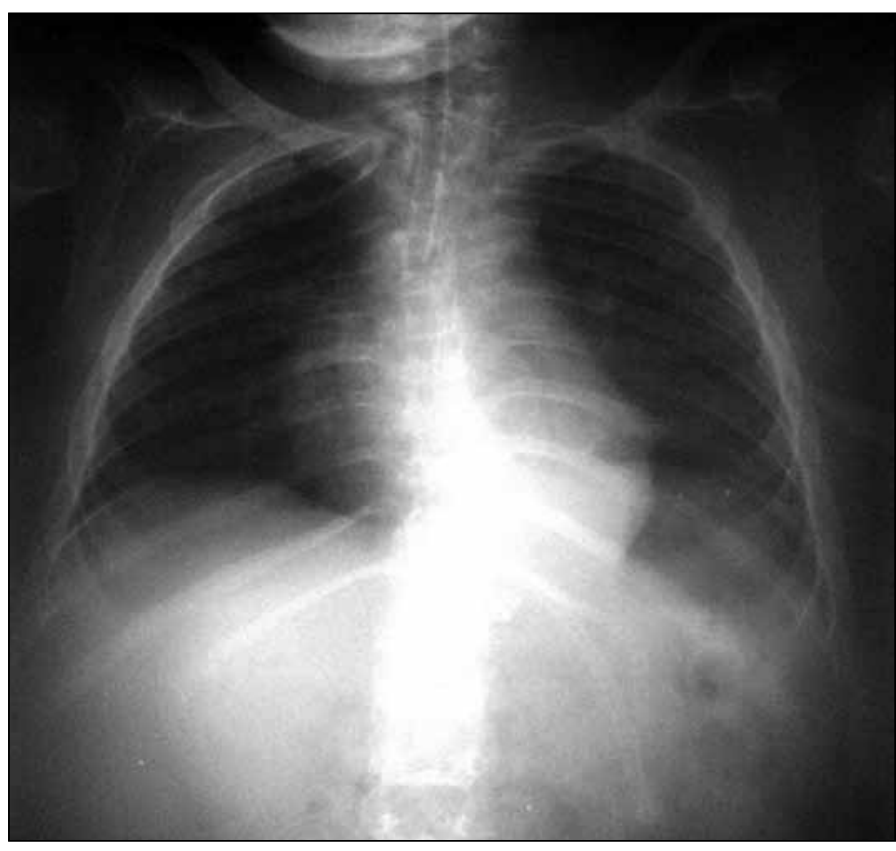

Şekil 3: Skolyoz, platispondili ve ayrıca kostalarda düzleşme gözlenmektedir. 


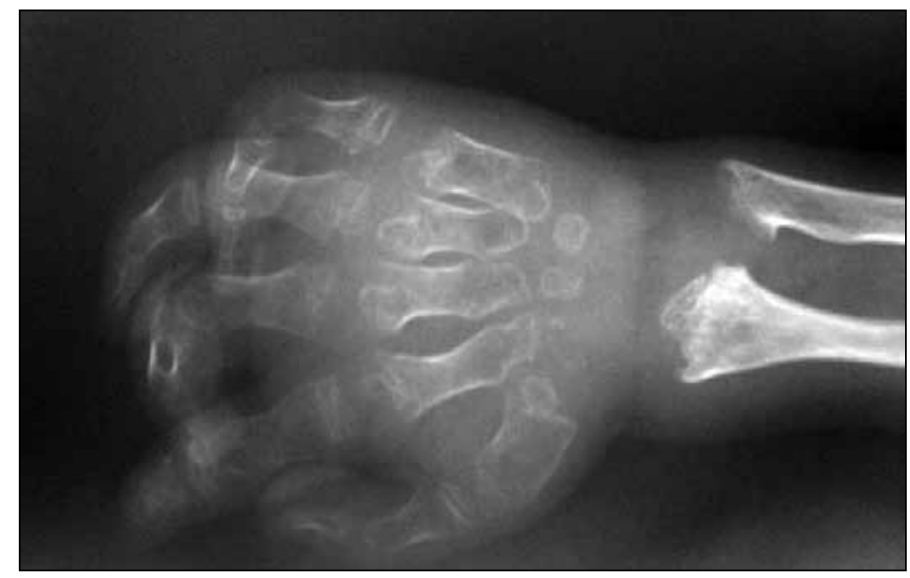

Şekil 4: Metafizler kısa ve kalın, epifizyal düzensizlik, osteoporoz gözlenmektedir.

servikal myelopati açısından beyin cerrahisi kliniği ile konsülte edilen hastaya servikal manyetik rezonans görüntüleme önerildi, ancak hastanın genel durumu uygun olmadığından yapılamadı. Mevcut bulgularla MPS şüphesi devam eden hastadan idrar ve kan örneği alınarak enzim çalısması için uygun koşullarda yurtdışına gönderildi.

Yoğun bakım ünitesinde, solunum zorluğu ve akciğer enfeksiyonu nedeni ile mekanik ventilatöre bağlı olarak izlenen hasta, denenmesine rağmen ekstübe edilemedi ve yaklaşık 3 aylık sürenin sonunda kardiyak arrest gelişerek kaybedildi.

MPS açısından gönderilen enzim çalışmasının sonuçları daha sonra elde edilen hastanın tekrarlanan idrar tetkiklerinde, oligosakkaritler ve siyalik asitin yaşına göre normal sınırlarda olduğu, ancak keratan sülfat düzeyininin arttığı ve dermatan sülfatın az miktarda saptandığı bildirildi. Kanda, Galaktoz6-sulfataz düzeyi $20 \mathrm{pmol} / \mathrm{mg} / \mathrm{h}$ ( $\mathrm{NR}=400$ - 2000, in-assay control 517), Beta-galaktozidaz: $160 \mathrm{nmol} / \mathrm{mg} / \mathrm{h} \quad(\mathrm{NR}=100$ - 400, in-assay control 114) bulundu ve bu sonuçlarla hastaya MPS IVA (Morquio A) tanısı konuldu.

\section{TARTIŞMA}

Morquio sendromu, büyüyen çocukta yaşam boyu giderek artan ve çeşitli şiddette olabilen iskelet deformitelerine yol açan otozomal resesif bir bozukluktur. Illk kez 1929'da Luis Morquio ve James Brailsford tarafından tanımlanmıştır. Sıklığı farklı ülkelerde 1/76.000 ile 1/450.000 canlı doğumda bir olarak bildirilmiştir $(8,9)$. Ülkemizdeki sıklığı tam olarak bilinmemekle birlikte büyük merkezlerimizden birinde yapılan bir çalıșmada 30 yılda 177 hastaya MPS tanısı konduğu, bu hastaların, 41'inin (\%23) MPS tip IV ve 21'inin ise MPS tip IVA olduğu bildirilmiștir. Bu çalıșmada, MPS tipleri sıklık sırasına göre MPS tip III, IV, VI, I, II ve VII olarak bulunmuștur (10). Ülkemizde bu konuda çalısılan en geniş seri olması nedeniyle Türkiye'deki MPS'ların tiplere göre dağılımının genel olarak bu dağııma uygun olduğu düșünülebilir. Klinik olarak platispondili, torasik kifoz ve skolyoz,
C1/C2 segment instabilitesi ile birlikte odontoid çıkıntı aplazisi, epifizyal displazi, alt ekstremitelerde valgus deformitesi, pes planus, sternumda belirginleșme, gargoylism ile birlikte bașta deformiteler, skafosefali, valvuler aort hastalıkları ve diffüz korneal opasifikasyon gözlenebilir. Bizim hastamızın annebabası arasında akrabalık olması, atipik-kaba yüz görünümü, pektus karinatus deformitesi, torakolomber kifoz ve skolyozunun mevcut olması, alt ekstremitelerinde valgus deformitesinin saptanması MPS ile uyumlu bulunmuştur. Hastamızın kardiak muayenesinde üfürüm fark edilmesine rağmen, yoğun bakım şartlarından dolayı ekokardiyografik inceleme yapılamamıștır. Hafif zeka geriliği olduğu ifade edilen hastanın iskelet grafilerinde tüm ekstremitelerin metafizleri geniş, epifizleri düzensiz, metakarplar ve falankslar kısa ve kalın, her iki taraf femur boynunda valgus deformitesi saptanması MPS Tip IV ile uyumlu bulunmuş ve enzim tayini ile tanı doğrulanmıştır.

MPS'li hastalarda dokulardaki birikim fetal dönemde başlamakla birlikte, etkilenmiş yenidoğanlar sıklıkla asemptomatiktir. Hastalığın şiddetine bağlı olarak ylllar içinde belirti ve bulgular ortaya çıkmaya başlar. Bizim hastamızın da şikayetleri 3 yașından sonra bașlamıştır. Bu hastalar için terapötik yaklaşımlar, eksik olan enzimin yerine konması (Tip I, II ve IV için onaylanmış ERT mevcut ve diğer tipler için geliştirime aşamasındadır); hematopoietik kök hücre transplantasyonu ve deneysel gen tedavileri şeklinde özetlenebilir (11-15). Genel olarak ERT, büyümeyi ve yaşam kalitesini olumlu yönde etkilemektedir ancak tedavinin başarılı olabilmesi için hastalığın erken dönemlerinde başlanması gerekir. Bu nedenle hastalığın erken dönemde tanınmasını ve asemptomatik bireylerin taranmasını sağlayan duyarlı ve özgül testlerin kullanıması gerekmektedir.

MPS IVA tanısı için idrarda total GAG bakmak ilk basamak tetkikleri arasında uygulanan bir yöntemdir ve genellikle spektrometrik yöntemle çalışlır $(16,17)$. Ancak hastaların yaklaşı \%20'sinde idrardaki total GAG düzeyleri, normal sağlıklı bireylerle aynı düzeylerde bulunmaktadır (18). Bu nedenle hasta bireyleri ayırt etmekte idrar GAG düzeyleri yetersizdir. Bizim hastamızda da idrarda total GAG düzeyi normal bulunmuștur.

Hastalıkla ilgili diğer potansiyel tanı aracı kanda ya da idrarda KS düzeyinin bakılmasıdır. Kanda KS düzeylerinin ölçümü, hastalığın tanısı için olduğu kadar prognoz ve tedavi etkinliğinin değerlendirilmesinde de kullanılabilmektedir (19). Biyolojik sıvilarda KS düzeyinin ölçümü için geliştirilmiş mevcut birçok yöntem bulunmakla beraber çoğunun duyarlılığı düşük, laboratuvar çalışmaları çok aşamalı ya da çok sayıda örneğin aynı anda çalışılmasına olanak vermeyen yöntemlerdir (18,2023). Yakın zamanda geliştirilen likit kromatografi tandem mass spektrometri (LC/MS/MS) yöntemi duyarlı, özgül ve kolay tekrarlanabilir bir yöntem olması sebebiyle tercih edilebilir (24). Yenidoğan döneminde tandem mass ile MPS taraması yapılabileceğini bildiren çalışmalar da bulunmaktadır (25).

KS temel olarak kartilajda sentez edilir ve MPS IVA'da birikerek ağır iskelet displazisine yol açar. Etkilenmemiş sağlıkı çocuklarda 
da yüksek kartilaj döngüsü nedeniyle, yüksek KS düzeyleri bulunabilir. Sağlıkı çocuklarda yaşa özgü olarak KS düzeylerinin, 5 yaşına kadar ilerleyici olarak arttığı, 10-12 yaşlarına kadar yüksek kaldı̆̆ı, daha sonra azalarak 15 yaşından sonra stabil hale geldiği gösterilmiștir $(26,27)$. Uzun kemiklerin büyümesi, yeni kartilajin parçalanmadan ve kemikle yer değiştirmeden önce sürekli yeniden oluşması ve endokondral kemikleșme sürecinden geçmesi ile olur. Yaklaşık 12 yaşından sonra gözlenen azalmış KS düzeyleri bu yaştan sonra büyüme hızının genellikle azaldığı gerçeğiyle doğru orantılıdır. MPS IVA'lı hastalarda da ortalama kan KS konsantrasyonu 5 yaşından önce en yüksektir, 10 yaşından sonra ise çoğu hastada normal ya da normale yakın düzeylere iner. Bu hastalarda kandaki KS düzeyleri hem sağılıklı çocuklarda gözlendiği gibi normal olgunlaşma ile ilgili değişikliklere hem de ilerleyici kondrodisplazinin șiddetine bağlıdır (28). Hastaların KS düzeylerini değerlendirirken bu durumu da göz önünde bulundurmak gerekir. Bizim hastamı tanı anında 11 yaş 2 aylık olup idrarda KS düzeyinin arttığı saptanabilmiştir.

MPS IVA'nın allelik heterojenitesinin tanımlanması, insan GALNS proteinini kodlayan DNA zincirinin izolasyonu ile kolaylaşmışıtı (29). GALNS geni 16q24 bölgesinde yerleșmiş, 14 ekzon ve 13 intron içeren, 35 kb büyüklüğünde bir gendir. Bugüne kadar farklı klinik fenotiplerden sorumlu birçok mutasyon tanımlanmıştır. Genetik çalışma özellikle taşıyıcıların belirlenmesi ve prenatal tanı için önemli olmakla birlikte tanımlanmış mutasyonlar ve polimorfizmlerin sayıca çokluğu sebebiyle pratikte kullanımı yaygın değildir $(30,31)$.

Ülkemizdeki akraba evliliklerinin sıklı̆ı göz önüne alındığında, belirti ve bulguların MPS IVA gibi otozomal resesif geçişli hastalığı düşündürdüğü durumlarda, enzim düzeyi çalışılması için ısrarlı olunmalı ve GAG ya da KS düzeylerinin yanıltıcı olabileceği akıldan çıkartımamalıdır. Yakın gelecekte tedavi şansı olabilecek gibi görünen bu hastaların erken tanısı, etkilenmiş bireylere daha erken dönemde ve etkin bir şekilde yardımcı olunmasını sağlayacaktır.

\section{KAYNAKLAR}

1. Meikle PJ, Hopwood JJ, Clague AE, Carey WF. Prevalence of lysosomal storage disorders. J Am Med Assoc 1999; 281: 249-54.

2. Fuller M, Rozaklis T, Ramsay SL, Hopwood JJ, Meikle PJ. Diseasespecific markers for the mucopolysaccharidoses. Pediatr Res 2004; 56: 733-8.

3. Neufeld E, Muenzer J. The mucopolysaccharidosis. In: Scriver C, Beaudet A, Sly W, Valle D (eds). The Metabolic and Molecular Bases of Inherited Diseases. New York: McGraw-Hill, 2001:342152.

4. Montaño AM, Tomatsu S, Gottesman G, Smith M, Orii T. International Morquio A registry: clinical manifestation and natural course of Morquio A disease. J Inherit Metab Dis 2007; 30:165-74.
5. Tomatsu S, Montaño AM, Gutierrez M, et al. Characterization and pharmacokinetic study of recombinant human $\mathrm{N}$-acetylgalactosamine-6-sulfate sulfatase. Mol Genet Metab 2007; 91: 69-78.

6. Tomatsu S, Montaño AM, Ohashi A, et al. Enzyme replacement therapy in a murine model of Morquio A syndrome. Hum Mol Genet 2007; 17: 815-24.

7. Rohrbach M, Clarke J. Treatment of lysosomal storage disorders: Progress with enzyme replacement therapy. Drugs 2007; 67: 2697-716.

8. Nelson J. Incidence of the mucopolysaccharidoses in Northern Ireland. Hum Genet 1997;101:355-8.

9. Pinto R, Caseiro C, Lemos M, Lopes L, Fontes A, Ribeiro H, et al. Prevalence of lysosomal storage diseases in Portugal. Eur $\mathrm{J}$ Hum Genet 2004;12: 87-92.

10. Kılıç M, Kalkanoglu Sivri HS, Tokatlı A, Dursun A, Coşkun T. Mukopolisakkaridozlar: 30 Yıllık Hacettepe Deneyimi. J LSD 2010; 2: 83.

11. Kakkis ED, Muenzer J, Tiller GE, Waber L, Belmont J, Passage $\mathrm{M}$, et al. Enzyme-replacement therapy in mucopolysaccharidosis I. New Engl J Med 2001; 344: 182-8.

12. Muenzer J, Wraith JE, Beck $M$, et al. A phase $\|/ /\|$ clinical study of enzyme replacement therapy with idursulfase in mucopolysaccharidosis II (Hunter syndrome). Genet Med 2006; 8: 465-73.

13. Harmatz P, Giugliani R, Schwartz IV, Guffon N, Teles EL, Miranda $\mathrm{MC}$, et al. Long-term follow-up of endurance and safety outcomes during enzyme replacement therapy for mucopolysaccharidosis, $\mathrm{VI}$, final results of three clinical studies of recombinant human $\mathrm{N}$-acetylgalactosamine 4-sulfatase. Mol Genet Metab 2008; 94: 469-75.

14. Gabrielli O, Clarke LA, Bruni S, Coppa GV. Enzyme-replacement therapy in a 5-month-old boy with attenuated presymptomatic MPS I: 5-year follow-up. Pediatrics 2010: 125; $183-7$.

15. Martins AM, Dualibi AP, Norato D, Takata ET, Santos ES, Valadares ER, et al. Guidelines for the management of mucopolysaccharidosis type I. J Pediatr 2009; 155: 32-46.

16. Whitley CB, Ridnour MD, Draper KA, Dutton CM, Neglia JP. Diagnostic test for mucopolysaccharidosis I. Direct method for quantifying excessive urinary glycosaminoglycan excretion. Clin Chem 1989; 35: 374-9.

17. Bjornsson S. Simultaneous preparation and quantitation of proteoglycans by precipitation with alcian blue. Anal Biochem 1993; 210: 282-91.

18. Tomatsu S, Okamura K, Taketani T, et al. Development and testing of new screening method for keratan sulfate in mucopolysaccharidosis IVA. Pediatr Res 2004; 55: 592-7.

19. Tomatsu S, Montaño AM, Ohashi A, Oikawa H, Oguma T, Dung VC, et al. Enzyme replacement therapy in a murine model of Morquio A syndrome. Hum Mol Genet 2008; 17: 815-24.

20. Fujimoto A, Horwitz AL. Biochemical defect of non-keratansulfateexcreting Morquio syndrome. Am J Med Genet 1983; 15: 265-73.

21. Beck M, GlossI J, Grubisic A, Spranger J. Heterogeneity of Morquio disease. Clin Genet 1986; 29: 325-31.

22. Thonar EJ, Lenz ME, Klintworth GK, Caterson B, Pachman LM, Glickman P, et al. Quantification of keratan sulfate in blood as a marker of cartilage catabolism. Arthritis Rheum 1985; 28: 136776. 
23. Yamada H, Miyauchi S, Morita M, Yoshida Y, Yoshihara Y, Kikuchi $\mathrm{T}$, et al. Content and sulfation pattern of keratan sulfate in hip osteoarthritis using high performance liquid chromatography. J Rheumatol 2000; 27: 1721-4.

24. Oguma T, Tomatsu S, Okazaki O. Analytical method for determination of disaccharides derived from keratan sulfates in human serum and plasma by high-performance liquid chromatography/ turbo-ionspray ionization tandem mass spectrometry. Biomed Chromatogr 2007; 21: 356-62.

25. Khaliq T, Sadilek M, Scott CR, Turecek F, Gelb MH. Tandem mass spectrometry for the direct assay of lysosomal enzymes in dried blood spots: application to screening newborns for mucopolysaccharidosis IVA. Clin Chem 2011; 57: 128-31.

26. Tomatsu S, Okamura K, Taketani T, Orii KO, et al. Keratan sulfate levels in mucopolysaccharidoses and mucolipidoses. J Inherit Metab Dis 2005; 28: 187-202.

27. Thonar EJ, Pachman LM, Lenz ME, Hayford J, Lynch P, Kuettner $\mathrm{KE}$. Age related changes in the concentration of serum keratan sulphate in children. J Clin Chem Clin Biochem 1988; 2: 57-63.
28. Tomatsu S, Montaño AM, Oguma T, Dung VC, Oikawa $H$, de Carvalho TG, et al. Validation of keratan sulfate level in mucopolysaccharidosis type IVA by liquid chromatographytandem mass spectrometry. J Inherit Metab Dis 2010; [Epub ahead of print].

29. Tomatsu S, Fukuda S, Masue M, Sukegawa K, Fukao T, Yamagishi $\mathrm{A}$, et al. Morquio disease: isolation, characterization and expression of full-length cDNA for human Nacetylgalactosamine-6-sulfate sulfatase. Biochem Biophys Res Commun 1991; 181: 677-82.

30. Baker E, Guo XH, Orsborn AM, Sutherland GR, Callen DF, Hopwood $\mathrm{JJ}$, Morris CP. The morquio A syndrome (mucopolysaccharidosis IVA) gene maps to 16q24.3. Am J Hum Genet 1993; 52: 96-8.

31. Tomatsu S, Montano AM, Nishioka T, Gutierrez MA, Pena OM, Tranda Firescu GG, et al. Mutation and polymorphism spectrum of the GALNS gene in mucopolysaccharidosis IV A (Morquio A). Hum Mutat 2005; 26: 500-12. 